\title{
ESTUDIO DE CASO: ANÁLISIS DE LAS ACTIVIDADES Y ESTRATEGIAS SOCIOAFECTIVAS APLICADAS EN LOS GRADOS DE SEXTO Y SÉPTIMO EGB, DE LA UNIDAD EDUCATIVA «CHARASOL»
}

\section{A CASE STUDY: ANALYSIS OF SOCIAL-AFFECTIVE ACTIVITIES AND STRATEGIES APPLIED IN SIXTH AND SEVENTH EGB GRADES OF THE «CHARASOL» EDUCATIONAL UNIT}

Steeven Andrés Moreira Cedeño ${ }^{1}$

https://orcid.org/0000-0001-6696-4185

Roger Geovanny Ibáñez Cuenca ${ }^{2}$ https:// orcid.org/0000-0003-2819-8795

Andrea Eloisa Monroy Villón ${ }^{3}$ https://orcid.org/0000-0003-1419-3731

Recibido: marzo 5, 2021 - Aceptado: abril 23, 2021

\section{RESUMEN}

El presente estudio se realizó en las aulas de sexto y séptimo año de educación básica, en la Unidad Educativa «Charasol», Ecuador. En un lapso de ocho semanas, se observaron las acciones didácticas de los docentes, enfocadas en estrategias socioafectivas, escenario y ambiente de aprendizaje de los salones de clases. Los docentes y los estudiantes tuvieron dificultades comunicativas e interpersonales al relacionarse dentro y fuera del aula; no se percibió un clima de confianza y de comunicación.

1 Licenciado en Ciencias de la Educación Básica, Universidad Nacional de Educación, Ecuador. Especialización en Educación Básica en Contextos Rurales, Universidad Austral, Argentina. Maestría en Docencia Universitaria, Universidad Europea del Atlántico, Santander, España. Docente, tutor, investigador, Universidad Nacional de Educación, Ecuador. samoreira636@gmail.com steeven.moreira@unae.edu.ec

2 Licenciado en Ciencias de la Educación Básica, Universidad Nacional de Educación, Ecuador. Docente, tutor en la Universidad Nacional de Educación, Ecuador. ji mh.roger@hotmail.com roger.ibanez@unae.edu.ec

3 Licenciada en Educación Intercultural Bilingüe, Universidad Nacional de Educación (UNAE), Ecuador. Docente, tutor en la Universidad Nacional de Educación, Ecuador. andreamonvi@hotmail.com andrea.monroy@unae.edu.ec 
Es por este motivo que se propuso registrar las aristas y los factores que intervienen en la acción y el rol didáctico del docente, con el objetivo de analizar y proponer una guía didáctica que destaque el uso y la importancia de estrategias socioafectivas, para mejorar el escenario y ambiente de aprendizaje en el subnivel de Educación Básica Media. El trabajo se basa en una investigación cualitativa que por medio de la observación, delimita situaciones manifestadas en las diferentes aulas de clases; además se destaca que la fuente primaria de información son los actores del aula y los investigadores, intérpretes de las situaciones observadas.

Luego del análisis de la información recolectada y la búsqueda bibliográfica se sustenta, fundamenta y se recomienda la creación de una Guía didáctica de estrategias socioafectivas esperando que, al ser implementada, los docentes planifiquen sus clases para satisfacer las necesidades de los estudiantes, y así crear un adecuado escenario y ambiente de aprendizaje en su aula de clases.

Palabras clave: estrategias socioafectivas, guía didáctica, ambientes de aprendizaje, escenarios de aprendizaje, aprendizaje afectivo, estrategias de aprendizaje.

\section{ABSTRACT}

The present work was carried out in the classrooms of third and seventh year of basic education over a period of eight weeks, where the same problem was observed: teachers and students have a difficulties communication and interpersonal relationship when relating inside and outside the classroom, too was not perceived a climate of trust and open communication, that is, not fulfilled one of the aspects of Ecuadorian education, the education that not only should be taught with quality, it should also be taught with warmth.

It is for this reason that we proposed to design a Didactic Guide that emphasizes the use and importance of socio-affective strategies to improve the learning scenario and environment. The work is based on a qualitative research that by means of observation delimited situations manifested in the different classrooms, in addition it is emphasized that the primary source of information are the actors of the classroom and the researcher an interpreter of the observed situations.

After the analysis of the information collected and the bibliographic search, a Didactic Guide of Socio-affective Strategies for the improvement of the learning scenario and environment is supported, founded and developed, hoping that, when implemented, the teacher will plan his 6classes to satisfy the needs of the students and create an adequate learning scenario and environment in his classroom.

Keywords: Socio-affective Strategies, Didactic guide, Learning environments, Learning scenarios, Affective learning, Learning strategies. 


\section{INTRODUCCIÓN}

El presente estudio surgió de las observaciones y la experiencia obtenida de la práctica profesional desarrollada en los grados de sexto y séptimo año de Educación General Básica (EGB), de la Unidad Educativa «Charasol», ubicada en el cantón de Azogues, provincia de Cañar, Ecuador. Dicha institución comprende desde Educación Inicial (EI) hasta Bachillerato General Unificado (BGU), y atiende a estudiantes provenientes de familias inmigrantes y de contextos rurales.

La práctica profesional fomenta y desarrolla una formación académica sujeta a las realidades de la labor docente en contextos reales. A su vez, incentiva y desarrolla la competencia de la observación e investigación. Es así que durante ocho semanas, del período lectivo 20192020, se observó y reflexionó la acción didáctica de los docentes de sexto y séptimo EGB. En este tiempo, se identificaron las incidencias y los factores claves en la interrelación entre docente-estudiante y estudiantes-estudiantes.

Este proceso de carácter exploratorio, implementó una metodología de investigación cualitativa, siendo la observación la principal herramienta para recopilar y analizar los datos. Se determinó estudiar las acciones y estrategias socioafectivas que los docentes aplicaron dentro y fuera del aula, por medio de la utilización y registros en diarios de campos, mismos que posteriormente se analizaron y nos permitieron identificar, comprender y analizar aspectos claves de la acción didáctica, entre ellos la importancia de conocer el contexto, escenario y ambiente de aprendizaje. Estos conceptos son claves en la formación y práctica del docente.

Las acciones o estrategias socioafectivas son un conjunto de actividades de carácter social y emocional, las cuales intervienen en procesos de comunicación, interrelación e inteligencia emocional por parte del docente. Estas estrategias se desarrollan dentro y fuera del aula, y en las mismas se involucra la planificación docente según el contexto, escenario y ambiente de aprendizaje. La literatura nos menciona que la labor del docente es de guía-mediador y debe convertirse en un actor activo, capaz de socializar y modelar valores, transmitir confianza, seguridad y, sobre todo, respeto y estima en sus estudiantes.

Por consecuencia, partiendo de las observaciones y el registro de las acciones y estrategias socioafectivas en las aulas de los grados sexto y séptimo de EGB, se procede a analizar los datos recopilados por medio del estudio y la literatura especializada en autores como De Beauport (2008), Rosas (2007), Romero (2008) y Efstathios (2017). Dichos autores concluyen que las estrategias socioafectivas son de vital importancia en la planificación y labor docente, pues incentivan y mejoran las relaciones interpersonales en el aula, y propician un clima psicoemocional proactivo. Por lo tanto, se infiere, analiza y se construye una reflexión crítica con el objetivo de analizar las acciones didácticas referentes a las estrategias socioafectivas, aplicadas por los docentes de sexto y séptimo EGB de la Unidad Educativa «Charasol».

El desarrollo y la implementación de acciones o estrategias socioafectivas -partiendo de la correcta planificación y atención al contexto de los estudiantes-, desarrollan habilidades actitudinales, conductuales y emocionales en los estudiantes, además de crear una interrelación docente-estudiante y estudiante-estudiante de manera eficiente, que potencie un escenario y ambiente de aprendizaje, claves para generar un aprendizaje significativo. Para cumplir el objetivo declarado, se proponen como objetivos específicos:

a) Identificar las acciones y estrategias socioafectivas realizadas por los docentes de las aulas de sexto y séptimo EGB.

b) Fundamentar teórica-metodológicamente los conceptos de estrategias socioafectivas, escenario y ambiente de aprendizaje. 
c) Analizar los resultados obtenidos de las observaciones de las estrategias socioafectivas, aplicados aplicadas en las aulas.

A continuación, se establece un marco de referencia con base en la consulta de literatura especializada, este apartado tiene como punto de partida, una mirada conceptual del currículo de educación general básica subnivel medio. Posteriormente se introducen las teorías que soportan el aprendizaje afectivo, mismo que define las acciones del rol docente frente a los conceptos de estrategias socioafectivas, escenarios y ambiente de aprendizaje. Se propone una discusión de los conceptos de los autores con la experiencia de las observaciones registradas para, finalmente, llegar a una contextualización de los conceptos claves que interfieren en la acción docente.

Al final se detalla el proceso metodológico para la creación de estrategias socioafectivas y se describe el proceso investigativo que conllevó: observación, registro y análisis de las acciones o estrategias socioafectivas realizadas por los docentes de sexto y séptimo EGB, de la Unidad Educativa «Charasol».

\section{MARCO DE REFERENCIA}

Las acciones didácticas de los docentes de las aulas de sexto y séptimo EGB, están sujetas a lo establecido en el currículo de Educación General Básica Media (2016), el cual integra los grados de quinto, sexto y séptimo EGB. Este subnivel educativo se caracteriza por vincular los objetivos del «Buen vivir»; el docente debe apoyar a la compresión y producción de textos escritos, orales, utilización de herramientas tecnológicas, el trabajo colaborativo y la comunicación e interrelación, dentro y fuera del aula (Ministerio de Educación, 2016).

Partiendo de esta premisa, en el subnivel de Educación Básica Media, el docente debe desarrollar habilidades sociales, emocionales y comunicativas en los estudiantes, mismas que deberán sujetarse a lo establecido en el artículo 2, literal I, de la Ley Orgánica de Educación Intercultural (LOEI, 2011):

Educación en valores.- La educación debe basarse en la transmisión y práctica de valores que promuevan la libertad personal, la democracia, el respeto a los derechos, la responsabilidad, la solidaridad, la tolerancia, el respeto a la diversidad de género, generacional, étnica, social, por identidad de género, condición de migración y creencia religiosa, la equidad, la igualdad, y la justicia y la eliminación de toda forma de discriminación.

Es importante mencionar, que en Ecuador, la labor docente está sujeta a la base legal y normativa de la Ley Orgánica de Educación Intercultural (LOEI, 2011), misma que destaca los lineamientos de la educación en el sistema educativo ecuatoriano. El mismo dictamen, también conlleva citar el artículo 11, que menciona las obligaciones de los docentes, entre las cuales resaltamos:

e. Respetar el derecho de las y los estudiantes, y de los miembros de la comunidad educativa, a expresar sus opiniones fundamentadas y promover la convivencia armónica y la resolución pacífica de los conflictos; 
f. Fomentar una actitud constructiva en sus relaciones interpersonales en la institución educativa; i. Dar apoyo y seguimiento pedagógico a las y los estudiantes, para superar el rezago y dificultades en los aprendizajes y en el desarrollo de competencias, capacidades, habilidades y destrezas.

Referenciamos dichos marcos normativos de acuerdo al análisis que en el siguiente apartado se contrarrestará con los registros de las acciones didácticas observadas en los docentes de sexto y séptimo EGB. Mientras tanto, señalamos que el sistema educativo ecuatoriano se estructura en función a una educación socioafectiva de valores, y en atender y contextualizar la enseñanza según las necesidades de los estudiantes.

El docente, dentro del sistema educativo ecuatoriano, es el regulador y facilitador de los procesos de enseñanza-aprendizaje. Él mismo debe caracterizarse por generar una comunicación efectiva. Este proceso conlleva aspectos socioafectivos y aquí radica la importancia y el objetivo de fundamentar, teórica y metodológicamente, las incidencias del aprendizaje afectivo.

El aprendizaje afectivo juega un rol importante en el proceso de enseñanza-aprendizaje y en las acciones didácticas realizadas por el docente. Las emociones que se expresen en el aula -y según cómo las perciban los estudiantes- tendrán un impacto psico-neuro-emocional que, dependiendo de la calidad emocional expresada, facilitarán o inhibirán lo percibido: en este caso, lo que el alumno está aprendiendo. De igual manera, el docente debe reconocer las emociones de sus estudiantes para que las mismas influyan en la correcta planificación y ejecución de su labor docente.

Las estrategias de aprendizaje afectivo también tienen respaldo desde las posturas constructivistas. Al respecto, Rosas (2007) señala que, para el constructivismo, los procesos de aprendizaje son transformaciones cognitivas a partir de una serie de fases, como son: motivación, aprehensión, adquisición, retención, recuerdo, desempeño y retroalimentación. En este sentido, las estrategias de aprendizaje afectivo convierten al docente en un ente motivador o un guía que, mediante actividades socioafectivas, logra un aprendizaje significativo en sus alumnos.

Romero (2008) define las estrategias socioafectivas como aquellas que permiten mejorar las relaciones interpersonales entre todos los miembros o integrantes de los procesos de educación; además, con la aplicación de este tipo de estrategias, se tiende a perder el miedo a la participación, a la opinión, se mejora la autoestima y el sentido de pertenencia y, por ende, se propicia un ambiente agradable de trabajo (p. 50).

Murcia (2012) menciona que:

Las estrategias socioafectivas se dirigen al estudiante para mejorar su competencia y habilidad social; evitando conflictos interpersonales, colaborando y compitiendo de forma adecuada, para permitir una mejora del proceso de recepción de la información: controlando, canalizando y reduciendo sentimientos de ansiedad, incompetencia o temor al fracaso (p. 49).

Además, el estudiante desarrolla autoconfianza, generando empatía y afectividad en su entorno social. En cambio, el docente se convierte en mediador, ejemplo y guía de la inserción socioafectiva y emocional del estudiante. Aquí radica la importancia del aprendizaje afectivo y del empleo de las estrategias socioafectivas.

El docente debe empoderar sus habilidades y competencias para desarrollar un aprendizaje afectivo y, por ende, estrategias socioafectivas. Al desarrollar una estrategia de 
aprendizaje debemos tener la cuenta que esta se diferencia según el objetivo y las condiciones del contexto que se presenten, para así poder elegir la adecuada. Al respecto, Yániz y Villardón (2006) reseñan las múltiples características que debe cumplir una estrategia socioafectiva:

a) Las estrategias deben ser funcionales y significativas.

b) La institución debe demostrar estrategias que pueden ser utilizadas: cómo aplicarse, cuándo y por qué son útiles.

c) Debe existir una conexión entre la estrategia enseñada y las percepciones del estudiante, sobre el contexto en que se desenvuelve.

d) Los estudiantes deben creer que las estrategias son útiles y necesarias.

e) Los objetivos de aprendizaje deben diseñarse teniendo en cuenta las características de la tarea, las exigencias del entorno, las propias limitaciones y los recursos personales.

Las autoras nos brindan un listado de condiciones claves que debe incluir una estrategia socioafectiva; sin embargo, es labor y competencia del docente diseñar, ejecutar y rediseñar las actividades que realice, para que sean funcionales y significativas. El docente planifica la actividad socioafectiva en función al contexto del estudiante; dicha actividad debe vincularse a los conocimientos previos y las situaciones socioafectivas de la cotidianidad. También nos mencionan las autoras, que la institución debe contener algún documento, guía o plan de estrategias previamente diseñadas, que el docente pueda aplicar.

En nuestra realidad investigativa, el Departamento de Consejería Estudiantil (DECE) de la Unidad Educativa «Charasol», contaba con un listado de cuatro estrategias socioafectivas que abordaremos en el siguiente apartado.

Es de suma importancia que, al momento de diseñar una estrategia socioafectiva, el docente advierta dos aspectos claves de la planificación: escenario y ambiente de aprendizaje. Los mismos fueron analizados en las observaciones realizadas y se procede a fundamentarlos teórica y metodológicamente.

Un escenario de aprendizaje se define como el espacio físico en donde el docente ejecuta su didáctica y metodología de clase. Según Efstathios (2017), un escenario pedagógico o de aprendizaje es una instancia de un modelo de diseño instruccional para un sujeto dado y un tipo de situación concreta. Básicamente define lo que los aprendices, y otros actores como el profesor, deben/pueden hacer con un conjunto, dados los recursos y las herramientas (2017, p. 3).

El docente domina y ejerce protagonismo en los escenarios de aprendizajes dentro de la institución, debido a que están sujetos a la organización del docente pero, en el exterior, él pierde el control de establecer y organizar un correcto escenario de aprendizaje. Sin embargo, debe brindar las destrezas y habilidades al estudiante para crear su propio escenario de aprendizaje y, a partir de esta situación, integrar, vincular y potenciarlas en el aula.

Del escenario de aprendizaje, surge el ambiente de aprendizaje. García (2014) menciona que un ambiente de aprendizaje se crea mediante espacios materiales físicos con un tipo de mobiliario, decoración y objetos específicos, donde el hombre realiza determinadas actividades respondiendo a ciertas características físicas, socioculturales, psicosociales, pedagógicas, que posibilitan promover el aprendizaje del alumno, volviéndose un lugar donde el estudiante pueda «reír, amar, jugar, encontrarse, perderse, vivir». 
En cambio, Viveros (2008) señala que el ambiente de aprendizaje se constituye a partir de las dinámicas establecidas en los procesos educativos y que involucran acciones, experiencias, vivencias para cada uno de los participantes; actitudes, condiciones materiales y socioafectivas, múltiples relaciones con el entorno y la infraestructura necesaria (p. 10).

Discrepamos con García (2014) en que el ambiente de aprendizaje no solo constituye espacios físicos de materiales. En una sociedad de conocimientos, con nativos digitales, el escenario y ambiente de aprendizaje se adaptó a un espacio virtual que es intangible, pero sí manipulable. Aunque en nuestro caso no surgió al tener un contexto rural, consideramos importante discrepar con el autor. Rescatamos conceptos de ambos autores y llegamos a la reflexión que los ambientes de aprendizaje son espacios de trabajo y convivencia, más que lugares de recepción y estudio. El ambiente de aprendizaje es un espacio intangible que involucra aspectos socioafectivos, comunicativos e interactivos.

Teniendo una aproximación a los conceptos de escenario y ambiente de aprendizaje, el docente está en la capacidad de desarrollar estrategias acordes a las necesidades de sus estudiantes. En este punto, citamos a Gutiérrez (2008) quien propone, para el docente, las siguientes claves para desarrollar una estrategia socioafectiva en el aula:

1. Observación de habilidades sociales. Observar las habilidades sociales que los estudiantes presenten en clase, y determinar situaciones que conlleven a la toma y resolución de problemas.

2. Escucha. Atender a los estudiantes, ser empático e identificar el estado emocional o algún problema que esté surgiendo, dentro o fuera del salón de clase.

3. Seguimiento de instrucciones. Instruir claramente, transmitir -de manera segura- emociones e instrucciones para, posteriormente, hacer seguimiento a las mismas en los estudiantes. Realizar una constante retroalimentación y un acompañamiento pedagógico.

4. Expresión de emociones. Desarrollar una inteligencia emocional eficiente: saber cuándo y cómo utilizar sus emociones. No deben tener miedo en demostrar emociones, incentivar la participación, y crear un ambiente de aprendizaje de franca comunicación y respeto.

Teniendo en cuenta las recomendaciones que nos brinda Gutiérrez (2008), y tomando las ideas de Yániz y Villardón (2006), y de Rosas (2007), proponemos el siguiente proceso metodológico para el diseño de una estrategia socioafectiva:

a) Definir el objetivo o los objetivos de aprendizaje.

b) Seleccionar la actividad o las actividades (opcionales y obligatorias) de aprendizaje, de acuerdo a los objetivos de aprendizaje.

c) Determinar con claridad los objetivos de cada actividad o estrategia.

d) Definir en términos muy claros los resultados de aprendizaje que se desean lograr.

e) Calcular el tiempo que se invertirá en su realización y planear la duración.

f) Definir los indicadores de evaluación del proceso y de los resultados. 
Es importante mencionar que el docente debe estar consciente que la aplicación de una estrategia no garantiza la totalidad del cumplimiento del objetivo general y de aprendizaje. El docente debe evaluar, analizar, reflexionar y rediseñar constantemente la estrategia. Yániz y Villardón (2006) destacan un listado de consideraciones que debemos tener presente al desarrollar una estrategia socioafectiva:

1. Una instrucción eficaz y con éxito, genera confianza y creencias de auto eficiencia.

2. La responsabilidad para generar, aplicar y controlar estrategias eficaces es transferida del instructor al estudiante.

3. Los materiales de instrucción deben ser claros, bien elaborados y agradables.

4. La enseñanza de estrategias presupone o demanda enseñar a los alumnos a ser estratégicos.

Estas consideraciones que nos brindan las autoras (2006) es importante tenerlas en cuenta aunque, obviamente, están presentes de manera implícita en la planificación docente y en su labor; sin embargo, en muchas ocasiones se pasan por alto y no se les presta atención.

Una vez abordados los aspectos claves, procedemos a evidenciar los registros de las observaciones realizadas.

\section{DESARROLLO}

El proceso investigativo del presente documento está sujeto a una metodología cualitativa, misma que busca descubrir todos los aspectos subjetivos que intervienen o afectan al tema específico que se investiga: en nuestro caso, las acciones o estrategias socioafectivas aplicadas de los docentes de sexto y séptimo EGB. En este punto, citamos a López y Lillo (2005): «la investigación cualitativa examina generalmente las palabras y las acciones humanas con un método narrativo o descriptivo, representando así la situación, como si los participantes la estuvieran experimentando» (p. 2). Por tal motivo, a continuación detallamos de manera narrativa y descriptiva todo el proceso de la recolección de datos, resultante de la observación y diarios de campos.

La observación, como técnica de investigación, es significativa al momento de identificar y analizar situaciones específicas de estudio. Esta habilidad -la de observar- consiste en conocer, identificar y comprender situaciones que surgen en un contexto o escenario de aprendizaje. Las mismas se registraron en los diarios de campos de cada investigador: escenarios de aprendizaje, ambientes de aprendizaje generados por los docentes, y actividades y estrategias socioafectivas que aplicaron del manual proporcionado por el DECE, en función a la normativa del artículo 12 de la LOEI. Toda esta información se analizó y sintetizó en la siguiente tabla: 
Tabla 1. Observaciones de las acciones docentes

\begin{tabular}{|c|c|c|}
\hline \multicolumn{3}{|c|}{ Registro de las observaciones } \\
\hline $\begin{array}{l}\text { Del artículo 12. Obligaciones } \\
\text { del docente }\end{array}$ & Docente de Sexto EGB & Docente de Séptimo EGB \\
\hline $\begin{array}{l}\text { e. Respetar el derecho de } \\
\text { las y los estudiantes, y de los } \\
\text { miembros de la comunidad } \\
\text { educativa, a expresar sus } \\
\text { opiniones fundamentadas, } \\
\text { y promover la convivencia } \\
\text { armónica y la resolución } \\
\text { pacífica de los conflictos. }\end{array}$ & $\begin{array}{l}\text { Se registró en muchas } \\
\text { ocasiones falta de respeto del } \\
\text { docente hacia los estudiantes } \\
\text { y viceversa. Las situaciones se } \\
\text { daban por indisciplina, falta de } \\
\text { instrucciones claras, abandono } \\
\text { del aula. El docente no } \\
\text { compartía las opiniones de los } \\
\text { estudiantes y recurría a muchas } \\
\text { actividades de humillación. } \\
\text { Se presentaron diversas } \\
\text { situaciones de conflictos y } \\
\text { el docente asumió acciones } \\
\text { negativas, y no las manejó de } \\
\text { manera asertiva. }\end{array}$ & $\begin{array}{l}\text { La docente respeta las } \\
\text { diferencias de los estudiantes. } \\
\text { Sin embargo, no fomenta } \\
\text { el respeto y la convivencia } \\
\text { entre estudiante-estudiante. } \\
\text { Se registraron situaciones de } \\
\text { conflicto y la docente buscaba } \\
\text { ayuda externa a la resolución } \\
\text { del problema. }\end{array}$ \\
\hline $\begin{array}{l}\text { f. Fomentar una actitud } \\
\text { constructiva en sus relaciones } \\
\text { interpersonales en la institución } \\
\text { educativa. }\end{array}$ & $\begin{array}{l}\text { Durante los ochos semanas de } \\
\text { observación, el docente realizó } \\
\text { pocas actividades de manera } \\
\text { constructiva. Su dinámica de } \\
\text { clase consistía en seguir las } \\
\text { instrucciones y orientaciones } \\
\text { del libro de trabajo. }\end{array}$ & $\begin{array}{l}\text { La docente realizaba } \\
\text { actividades en grupos, pero } \\
\text { no se evidenciaba un trabajo } \\
\text { colaborativo. Los estudiantes } \\
\text { no sabían trabajar en grupo y } \\
\text { se generaba indisciplina, y poca } \\
\text { atención y seguimientos de las } \\
\text { instrucciones de trabajo. }\end{array}$ \\
\hline $\begin{array}{l}\text { i. Dar apoyo y seguimiento } \\
\text { pedagógico a las y los } \\
\text { estudiantes, para superar el } \\
\text { rezago y dificultades en los } \\
\text { aprendizajes y en el desarrollo } \\
\text { de competencias, capacidades, } \\
\text { habilidades y destrezas }\end{array}$ & $\begin{array}{l}\text { El docente concentraba } \\
\text { su labor en seguir y dar } \\
\text { las instrucciones, como lo } \\
\text { establece el libro de trabajo. } \\
\text { No se evidenció un apoyo y } \\
\text { seguimiento pedagógico, dentro } \\
\text { ni fuera del salón del aula. }\end{array}$ & $\begin{array}{l}\text { La docente realizaba refuerzos } \\
\text { y acompañamiento pedagógico } \\
\text { a estudiantes con bajo } \\
\text { rendimiento, en los recesos y } \\
\text { en horas extracurriculares. Sin } \\
\text { embargo, consistía en repetir } \\
\text { las mismas instrucciones y } \\
\text { actividades realizadas en el } \\
\text { salón del aula. }\end{array}$ \\
\hline
\end{tabular}




\begin{tabular}{|c|c|c|}
\hline Contexto & Docente de Sexto EGB & Docente de Séptimo EGB \\
\hline $\begin{array}{l}\text { Característica de la localidad y } \\
\text { estudiantes. }\end{array}$ & \multicolumn{2}{|c|}{$\begin{array}{l}\text { Los estudiantes provienen de familias migrantes; la gran mayoría } \\
\text { viven con sus abuelos o familiares. Rondan entre los nueve y once } \\
\text { años de edad. Provienen de un contexto rural. La gran mayoría se } \\
\text { apoyan en actividades de ganadería y trabajan en las tardes. } \\
\text { La gran mayoría de los estudiantes no cuentan con apoyo de sus } \\
\text { familiares en la realización de los deberes. El acceso a Internet es } \\
\text { limitado. } \\
\text { Un porcentaje alto de los estudiantes viven en situaciones de } \\
\text { conflictos familiares graves y muy graves; envueltos en círculos } \\
\text { de consumos de alcohol, violencia familiar, entre otros problemas } \\
\text { sociales. }\end{array}$} \\
\hline Escenario de aprendizaje & Docente de Sexto EGB & Docente de Séptimo EGB \\
\hline Dentro del aula. & $\begin{array}{l}\text { El docente mantiene un } \\
\text { orden jerárquico en el aula; } \\
\text { los estudiantes con mejores } \\
\text { habilidades, dominio y } \\
\text { conocimiento se sientan al } \\
\text { frente de la clase. El salón es } \\
\text { simple, con buena iluminación, } \\
\text { pero con pocos recursos y } \\
\text { espacios de interacción. }\end{array}$ & $\begin{array}{l}\text { La docente ha diseñado } \\
\text { espacios de lecturas, de juegos } \\
\text { y de convivencia; sin embargo, } \\
\text { no se utilizan, debida a la falta } \\
\text { de control e indisciplina de los } \\
\text { estudiantes. La iluminación y el } \\
\text { espacio físico del aula es bueno, } \\
\text { pero desordenado. }\end{array}$ \\
\hline $\begin{array}{l}\text { Fuera del aula (patio, canchas, } \\
\text { exteriores del salón del aula). }\end{array}$ & \multicolumn{2}{|c|}{$\begin{array}{l}\text { La institución no cuenta con seguridad externa. El acceso es libre } \\
\text { y fuera de la institución se encuentra una calle principal de alto } \\
\text { tráfico vehicular. } \\
\text { El patio de la institución es amplio, con áreas verdes. La institución } \\
\text { cuenta con un laboratorio de computación que no funciona. No } \\
\text { poseen otros espacios, aparte de los salones de clases y el patio de } \\
\text { la institución. }\end{array}$} \\
\hline Ambiente de aprendizaje & Docente de Sexto EGB & Docente de Séptimo EGB \\
\hline Situación social. & $\begin{array}{l}\text { La interrelación docente- } \\
\text { estudiantes es escasa. El } \\
\text { docente cumple el rol de } \\
\text { comunicar e instruir la clase, de } \\
\text { manera directa y magistral. Se } \\
\text { evidenciaron pocas actividades } \\
\text { de trabajo colaborativo. El } \\
\text { ambiente de aprendizaje es de } \\
\text { poca comunicación, algo tenso } \\
\text { y muy estricto. }\end{array}$ & $\begin{array}{l}\text { La situación social del aula } \\
\text { es notablemente baja, los } \\
\text { estudiantes no se relacionan. } \\
\text { La docente trata de interactuar } \\
\text { con los estudiantes, pero sin } \\
\text { resultados relevantes. }\end{array}$ \\
\hline Situación emocional. & $\begin{array}{l}\text { Es evidente que los estudiantes } \\
\text { están preocupados, } \\
\text { desanimados y con temor. } \\
\text { El docente es estricto, poco } \\
\text { comunicativo y no expresa } \\
\text { emociones que incentiven un } \\
\text { ambiente de aprendizaje. }\end{array}$ & $\begin{array}{l}\text { La docente es muy emotiva: no } \\
\text { controla sus emociones frente } \\
\text { a un problema de interrelación } \\
\text { con sus estudiantes. Los } \\
\text { estudiantes son poco } \\
\text { comunicativos, se notan } \\
\text { preocupados y desanimados. }\end{array}$ \\
\hline
\end{tabular}

Fuente: Creación propia a partir de los diarios de campos. 
Las estrategias socioafectivas que el DECE compartió con los docentes son las siguientes:

- Primera actividad, «Rincón de las emociones». Su objetivo es ofrecer un primer acercamiento, de forma anónima y segura, entre docente-alumno. La actividad requiere solo de la elaboración de un mural con tres columnas específicas: «Me siento feliz porque...», «No me gusta la clase porque...», «Estoy molesto porque...». El docente debe explicar a los alumnos que en este espacio ellos podrán escribir pequeños mensajes, en cualquiera de las columnas, sea de forma anónima o con su nombre, además de comentar que este es un espacio que debe respetarse y el único que puede recoger los afiches es él/ella.

- Segunda actividad, «Mesa redonda». Tiene como objetivo brindar confianza, seguridad y autoestima en los estudiantes. Consiste en sentarse en círculo. El docente debe incentivar el diálogo mediante anécdotas y experiencias. Cabe recalcar que esta actividad debe cumplir un proceso de varias intervenciones debido a que, en la primera ejecución, es posible que los alumnos no participen de la mejor manera y no se cumpla con el objetivo de la actividad.

- Tercera actividad, «Diario de las emociones». Busca concientizar al alumno en su proceso de enseñanza y a controlar sus emociones. El alumno tendrá un cuaderno donde escribirá diariamente, o cuando desee, el estado de sus emociones y la perspectiva que tuvo de la clase. Asimismo, esta actividad debe cumplir un tiempo estimado de tres meses a todo el año educativo. Con esta actividad se pretende que el alumno tome conciencia y perciba la importancia de la escuela y el papel que juega el docente.

- Cuarta actividad, «Confío en ti». Tiene como objetivo desarrollar confianza entre los compañeros de la clase. Consiste en un juego donde el docente explica que se formarán grupos de dos personas: uno tendrá los ojos vendados y el otro se colocará detrás del primero. El primer estudiante debe dejarse caer hacia atrás, el segundo debe atraparlo y evitar que caiga. Esta actividad puede realizarse indistintamente las veces que el docente desee, eso sí, cambiando el nivel de confianza.

Estas estrategias socioafectivas fueron aplicadas por los docentes de sexto y séptimo EGB. Es importante mencionar que los docentes fueron previamente instruidos por el departamento del DECE sobre cómo emplear dichas estrategias, de las cuales obtuvimos los siguientes resultados:

Tabla 2. Análisis de las estrategias socioafectivas

\begin{tabular}{|c|c|c|}
\hline Estrategias socioafectivas & Docente de Sexto EGB & Docente de Séptimo EGB \\
\hline Rincón de emociones. & $\begin{array}{l}\text { El docente aplicó la estrategia } \\
\text { en su salón de clase por una } \\
\text { semana, de manera rígida y } \\
\text { muy directa. Los estudiantes } \\
\text { participaban con temor. Al } \\
\text { término de la primera semana, } \\
\text { el docente desistió y no volvió } \\
\text { utilizar la actividad. }\end{array}$ & $\begin{array}{l}\text { La docente aplicó la estrategia } \\
\text { sin éxito. Los estudiantes no } \\
\text { participaban. }\end{array}$ \\
\hline
\end{tabular}




\begin{tabular}{|c|c|c|}
\hline Mesa redonda. & $\begin{array}{l}\text { El docente realizó tres sesiones } \\
\text { de mesa redonda, la cual } \\
\text { consistió en que los estudiantes } \\
\text { escucharan sus anécdotas } \\
\text { y consejos de estudios. El } \\
\text { docente pidió participar a sus } \\
\text { estudiantes y no lo logró. }\end{array}$ & $\begin{array}{l}\text { La docente aplicó la estrategia } \\
\text { por tres semanas. Al inicio de } \\
\text { la semana (lunes) y final de la } \\
\text { semana académica (viernes). } \\
\text { En la primera sesión, ningún } \\
\text { estudiante participó. En la } \\
\text { segunda sesión, se presentó } \\
\text { un conflicto y la docente } \\
\text { supo utilizar el problema para } \\
\text { incentivar la comunicación. } \\
\text { La tercera sesión fue más } \\
\text { participativa; se comenzó } \\
\text { a crear un ambiente de } \\
\text { confianza. }\end{array}$ \\
\hline Diario de emociones. & \multicolumn{2}{|c|}{$\begin{array}{l}\text { Los docentes de sexto y séptimo utilizaron esta estrategia para } \\
\text { realizar tareas dirigidas a los estudiantes: ordenaban escribir } \\
\text { sobre un tema específico en el cuaderno de "Lengua y literatura". } \\
\text { No se siguieron las orientaciones proporcionadas por el DECE en } \\
\text { esta actividad. }\end{array}$} \\
\hline Confío en ti. & $\begin{array}{l}\text { El docente aplicó la actividad } \\
\text { con un poco de temor y } \\
\text { pocas expectativas de cómo } \\
\text { responderían los estudiantes. Se } \\
\text { evidenció participación de los } \\
\text { estudiantes; por momentos se } \\
\text { creó un ambiente de aprendizaje } \\
\text { lúdico, diferente de lo normal. } \\
\text { Sin embargo, se presentó } \\
\text { un conflicto y la decisión } \\
\text { del docente fue terminar la } \\
\text { actividad. }\end{array}$ & $\begin{array}{l}\text { La docente aplicó esta } \\
\text { actividad, sin embargo, por la } \\
\text { poca confianza e interrelación } \\
\text { con los estudiantes, no se } \\
\text { logró el objetivo esperado. } \\
\text { Durante la actividad, hubo } \\
\text { muchas situaciones de } \\
\text { conflictos y la docente } \\
\text { suspendió la actividad. }\end{array}$ \\
\hline
\end{tabular}

Fuente: Elaboración propia.

De los datos obtenidos como grupo, llegamos a las siguientes reflexiones:

Los docentes de sexto y séptimo de EGB cumplen parcialmente con las obligaciones del docente, declaradas en el artículo 12 de la LOEI (2011), máximo reglamento y norma legislativa en el Ecuador. Por tal motivo, se entiende que los docentes realizan su labor enfocada a lo establecido en el currículo y en el cuaderno de trabajo del docente, aunque se trata solo de una guía, por lo que el docente debe adaptar dichas instrucciones con base en las necesidades y características de sus estudiantes.

Los docentes de sexto y séptimo tienen dificultades al relacionarse con sus estudiantes, y los estudiantes no tienen la confianza necesaria para expresarse afectivamente en el salón de clases. El docente de sexto es muy rígido y estricto, todo lo contrario que la docente de séptimo. Dichas actitudes y situaciones, a pesar de ser contrarias, generan el mismo problema. $Y$ es aquí que la labor del docente requiere de equilibrio. 
Se evidencia la ausencia de comunicación afectiva entre los docentes y los estudiantes, debido a la falta de confianza. Murcia (2012) destaca que las estrategias socioafectivas se dirigen al estudiante para mejorar su competencia y habilidad social, esto genera que se cree en ellos confianza, autoestima y seguridad para participar e intervenir en clases.

Los estudiantes se sienten desmotivados en las clases, porque los docentes no proponen actividades motivadoras dentro del aula. Ambos docentes se rigen por las actividades propuestas en los libros del MINEDUC, pero para los estudiantes esto se vuelve una rutina que provoca -como ruta de salida- la indisciplina, dentro y fuera del aula: muestran una conducta impropia con sus compañeros y con los docentes. Esta situación fue cotidiana en el lapso de las ocho semanas de observación; las acciones de los docentes no respondieron al problema. Referente al tema, Vázquez (2016) indica que la presencia constante de problemas de conducta en un alumno suele desembocar en la presentación de necesidades educativas especiales (NEE), no solo porque no consigue adquirir las competencias socioafectivas mínimas en la asignatura de Formación Cívica y Ética, sino porque sus efectos negativos se expanden rápidamente al resto de su vida escolar, familiar y comunitaria.

El DECE implementó un taller de cuatro estrategias socioafectivas; sin embargo, las mismas no contemplaban las orientaciones e indicaciones expresadas por la literatura declarada en el presente documento. Se evidencia una planificación rápida, sin atender al contexto, sin ordenar ni planificar el escenario, y con poca preparación y capacitación a los docentes. No se declara un objetivo de aprendizaje ni la finalidad de realizar dichas actividades. En la primera actividad, denominada «El rincón de las emociones», se evidenció que los docentes no la implementaron de la mejor manera, debido a que ellos mismos no crearon el adecuado escenario ni el ambiente de aprendizaje apropiado.

En la segunda actividad, «Mesa redonda», se obtuvieron resultados distintos en cada salón de clase. En el aula de sexto el docente, al no incentivar la participación de sus estudiantes, no desarrolló una correcta interrelación con ellos; además, no evaluó la aplicación de la estrategia y repitió la actividad a pesar de los insuficientes resultados. En cambio, la docente de séptimo utilizó el contexto y las situaciones cotidianas de sus estudiantes para incentivar la participación: en cada sesión fue cambiando y mejorando.

En la tercera actividad, «El diario de las emociones», se evidenció que ambos docentes no siguieron las instrucciones ni el objetivo de la actividad: establecer un clima de confianza con los estudiantes. Utilizaron dicha actividad para la realización de tareas, lo que generó desmotivación y desinterés en los estudiantes.

Por último, la cuarta actividad «Confío en ti», obtuvo resultados similares en cada salón de clase. Al no saber orientar, establecer reglas y crear un ambiente de confianza en sus escenarios de aprendizaje, los docentes provocaron que se generaran situaciones de conflicto $y$, por ende, la suspensión de la actividad.

Esta situación, obtuvo resultados insuficientes en la aplicación de las cuatro actividades. Sin embargo, las actividades se basan en el principio de un aprendizaje afectivo y fue responsabilidad de los docentes el poco éxito de las mismas. Esto demuestra que, aunque se disponga de estrategias contextualizadas, sin el aporte y compromiso del docente, no se asegura la eficacia de las mismas.

A partir de los resultados expuestos, recomendamos la creación de una guía didáctica con base en la literatura declarada y seguir las orientaciones metodológicas de Gutiérrez (2008), 
Rosas (2007), y Yániz y Villarodón (2006), además de tener en cuenta las observaciones y la experiencia expuestas desde el papel por los observadores e investigadores para la creación de dicha guía didáctica.

\section{CONCLUSIONES}

La literatura declarada de autores como Rosas (2007) y Romero (2008), demuestra y resalta la importancia de las estrategias socioafectivas dentro de la educación. Las estrategias socioafectivas ayudan al docente y al estudiante a mejorar sus relaciones interpersonales y sociales, además de preparar al estudiante a enfrentar situaciones cotidianas para aprender a identificar, determinar, controlar y expresar sus emociones. En cambio, el docente debe identificar las necesidades y características peculiares y específicas de sus estudiantes, para lograr un equilibrio de emociones y un ambiente de aprendizaje de franca comunicación.

Los escenarios de aprendizajes y ambientes de aprendizajes son términos complementarios y subyacentes. El escenario de aprendizaje es el espacio -sea físico o virtual- y todo el material que el docente utiliza en el proceso de enseñanza-aprendizaje. El ambiente de aprendizaje es la acción e interrelación que se produce en el escenario de aprendizaje. Los docentes, a pesar de tener en su formación inicial el conocimiento de dichos términos, no reconocieron, identificaron ni planificaron en función de estos factores.

Se recomienda la creación de una guía de estrategias socioafectivas, en función de los resultados y el análisis de las observaciones declaradas. De igual forma, se sugiere capacitar a los docentes participantes en el estudio para construir conjuntamente nuevas actividades contextualizadas y que respondan a las necesidades de los estudiantes.

\section{REFERENCIAS}

Aguilar, R. (2004). La guía didáctica, un material educativo para promover el aprendizaje autónomo. Evaluación y mejoramiento de su calidad en la modalidad abierta y a distancia de la UTPL. Revista Iberoamericana de Educación a Distancia, 7(1/2), 179. https:// bit.ly/3oCU8vM

Efstathios, S. (2017). Escenario, contexto y ambiente de aprendizaje. https:/ / bit.ly/3oAE4uA

García, G. (2014). Ambiente de aprendizaje: su significado en educación preescolar. Revista de Educación y Desarrollo, 63-72. https:// bit.ly/3aAuCTh

Gutiérrez, C. (2008). Estrategias para mejorar las habilidades sociales en niños y niñas de parvulario del Colegio Montessori British School. Universidad de la Sabana. Instituto de posgrados. Especialización en Pedagogía e Investigación en el aula Facultad de Educación. Bogotá. https:// bit.ly/3pDXBM1

LOEI (2011) Artículo 2 y 11. Registro Oficial No. 417, del 31 de marzo del 2011. https://bit. ly/3oCsxLt 
López, I. y Lillo, R. (2010). Investigación cualitativa. España: Hurtado Ediciones.

MINEDUC (2012). Estándares de calidad educativa. https: / / bit.ly/3tdyoKD

MINEDUC (2016). Currículo de los niveles de educación obligatoria. https:/ / bit.ly/2NOPv5b

Murcia, G. (2012). Estrategias socioafectivas en la educación universitaria. Bogotá. https://bit. ly/3pG61m8

Romero, P. (2008). Pedagogía de la humanización. Bogotá: Editorial Bonaventuriana.

Rosas, L. (2007). Las estrategias socio-afectivas y su efecto motivador en situaciones de aprendizaje de una lengua extranjera. Paradigma, 28, 2, 181-196. Maracay. ISSN 10112251. https:// bit.ly/3jbDqTh

Viveros, P. (2008). Ambientes de aprendizaje; Una opción para mejorar la calidad de la educación. Universidad Euro Hispanoamericana. https:/ / bit.ly/2Ywl31V

Yániz, C. y Villardón, L. (2006). Planificar desde competencias para promover el aprendizaje. El reto de la sociedad del conocimiento para el profesorado universitario. Cuadernos monográficos del ICE, 12. Bilbao: ICE de la UD. 